\title{
Effects of gender and ethnicity on outcomes after aortic valve replacement
}

\author{
Sotiris C. Stamou, MD, PhD, ${ }^{\mathrm{a}}$ Michael Robich, MD, MSPH, ${ }^{\mathrm{b}}$ Robert E. Wolf, MS, ${ }^{\mathrm{c}}$ Ann Lovett, RN, MA, ${ }^{\mathrm{c}}$ \\ Sharon-Lise T. Normand, PhD, ${ }^{c, d}$ and Frank W. Sellke, MD
}

\begin{abstract}
Objective: To evaluate the clinical outcomes after aortic valve replacement or aortic valve replacement and coronary artery bypass grafting in a large contemporary population, and to determine if outcomes are associated with patient ethnicity and gender status.
\end{abstract}

\begin{abstract}
Methods: Using the Massachusetts Cardiac Surgery Database, we identified 6809 adults aged 18 years or older who had undergone isolated aortic valve replacement or aortic valve replacement and coronary artery bypass grafting in all non-federal acute-care Massachusetts hospitals from 2002 to 2008. Univariate and multivariate logistic regression analyses were used to identify differences in patient characteristics, major morbidity, and 30-day and 1-year mortality between men $(\mathrm{n}=4043)$ and women $(\mathrm{n}=2766)$ and between whites $(\mathrm{n}=6481)$ and nonwhites $(\mathrm{n}=328)$.
\end{abstract}

Results: The unadjusted 30-day mortality rate was $2.6 \%$ for the men and $3.1 \%$ for the women $(P=.296)$ and $2.8 \%$ for whites and $3.7 \%$ for nonwhites $(P=.342)$. In adjusted logistic regression models, the 30 -day mortality was not different between the female and male patients (odds ratio, $0.88 ; 95 \%$ confidence interval, 0.26-3.02, $P=.84$ ) nor between the nonwhites and whites (odds ratio, $1.57 ; 95 \%$ confidence interval, $0.45-5.44 ; P=.48$ ). The incidence of postoperative stroke was greater in women $(3.0 \%$ women and $2.2 \%$ men, $P=.031)$, and the incidence of postoperative myocardial infarction $(10.9 \%$ women and $13.6 \%$ men; $P=.001)$ and septicemia $(1.2 \%$ women and $2.0 \%$ men; $P=.009)$ was greater in men.

Conclusions: Ethnicity and gender were not associated with greater 30-day and 1-year mortality after aortic valve replacement or aortic valve replacement and coronary artery bypass grafting. Differences in postoperative outcomes were not observed between ethnic groups. (J Thorac Cardiovasc Surg 2012;144:486-92)

During the past few years, a growing number of studies have focused on the differences in outcome between men and women undergoing coronary artery bypass grafting $(\mathrm{CABG})$ or aortic valve replacement (AVR). ${ }^{1-4}$ Other studies have investigated the relationship between race and outcomes after AVR. ${ }^{5}$ Although many of those studies have examined gender and race differences in patients undergoing $\mathrm{CABG},{ }^{6,7}$ few have studied patients undergoing AVR. ${ }^{5,8}$ Previous studies have shown that black race and female gender are independent predictors of mortality after cardiac surgery. ${ }^{6,9,10}$ Despite the wealth of data

From the Division of Cardiovascular and Thoracic Surgery, ${ }^{a}$ Department of Surgery, Spectrum Health, Michigan State University, Grand Rapids, Mich; Division of Cardiothoracic Surgery, ${ }^{\mathrm{b}}$ Department of Surgery, Beth Israel Deaconess Medical Center, Harvard Medical School, Boston, Mass; Department of Heath Care Policy, ${ }^{c}$ Harvard Medical School, Boston, Mass; Department of Biostatistics, ${ }^{\mathrm{d}}$ Harvard School of Public Health, Boston, Mass; and Division of Cardiothoracic Surgery, Department of Surgery, Rhode Island Hospital and Brown University Warren Alpert School of Medicine, Providence, RI.

Disclosures: Authors have nothing to disclose with regard to commercial support.

Received for publication July 14, 2011; revisions received Oct 15, 2011; accepted for publication Nov 9, 2011; available ahead of print Dec 12, 2011.

Address for reprints: Frank W. Sellke, MD, Department of Surgery, Division of Cardiothoracic Surgery, Rhode Island Hospital and Brown University Warren Alpert School of Medicine, 593 Eddy Street, APC 424, Providence, RI 02903 (E-mail: fsellke@lifespan.org).

0022-5223/ $\$ 36.00$

Copyright (c) 2012 by The American Association for Thoracic Surgery doi:10.1016/j.jtcvs.2011.11.023 available on the predictors of outcome after CABG, we were not able to identify any study that explicitly investigated the influence of both race and gender on the outcomes of AVR or AVR and CABG.

The Massachusetts Cardiac Surgery Database provides a unique opportunity to address this important question using a contemporary state-mandated registry. Our study sought to answer the following questions. First, whether nonwhites have poorer outcomes after AVR or AVR and CABG compared with whites; and, second, whether women have worse outcomes after AVR or AVR and CABG compared with men.

\section{METHODS \\ Patients}

The Massachusetts Cardiac Surgery Database was queried and identified 6809 patients aged 18 years or older with aortic stenosis who underwent AVR or CABG and AVR from January 2002 to December 2008 in all non-federal acute care hospitals in Massachusetts. The baseline demographics, procedural data, and perioperative outcomes were recorded and entered prospectively in a prespecified database by dedicated hospital data managers. We identified 6879 patients with aortic stenosis undergoing isolated AVR or isolated AVR and CABG surgery from January 1, 2002 to September 30, 2008. We excluded 58 patients we could not assign to a mechanical or bioprosthetic prosthesis type and another 12 patients with missing race information. Of the remaining 6809 patients, 3 were removed from the multivariate analyses because of missing data for 1 or more model covariates. 


\section{Abbreviations and Acronyms}

AVR = aortic valve replacement

$\mathrm{CABG}=$ coronary artery bypass grafting

$\mathrm{CI}=$ confidence interval

$\mathrm{OR}=$ odds ratio

Long-term survival data were obtained from 3 different sources: hospital, Massachusetts Registry of Vital Statistics, and Social Security death index website (http://ssdi.rootsweb.ancestry.com/). Because Massachusetts hospitals are not required to report the long-term outcomes, we restricted the analysis of 1-year mortality to Massachusetts residents to ensure follow-up completeness.

\section{Study Design and Conduct}

This was a retrospective cohort study of prospectively collected data from consecutive patients who underwent AVR or AVR and CABG in Massachusetts. The institutional review board approved the study. Patient confidentiality was maintained at all times, consistent with the Health Insurance Portability and Accountability Act of 1996 regulations.

\section{Definitions}

The Society of Thoracic Surgeons' national cardiac surgery database definitions were used for this study. A history of stroke was defined as a history of central neurologic deficit persisting for more than 24 hours. Chronic renal insufficiency was defined as a serum creatinine value of $2.0 \mathrm{mg} / \mathrm{dL}$ or more. Diabetes was defined as a history of diabetes mellitus, regardless of the disease duration, or the need for oral diabetes agents or insulin. Postoperative stroke was defined as any new major (type I) neurologic deficit presenting in-hospital and persisting for longer than 72 hours. Acute renal failure was defined as 1 or both of the following: (1) an increase in the serum creatinine to more than $2.0 \mathrm{mg} / \mathrm{dL}$ and/or a greater than twofold increase in the most recent preoperative creatinine level; or (2) a new requirement for dialysis postoperatively.

\section{Statistical Analysis}

Univariate analysis. Univariate comparisons of the preoperative, operative, and postoperative variables were performed between men and women and between white and nonwhite patients. Continuous variables were summarized using the mean, median, and range, and frequencies and percentages are reported for categorical variables. Continuous variables were tested using the $t$ test, and categorical variables were assessed using the chi-square test or Fisher's exact test, depending on the distribution of the data. $P<.05$ was considered statistically significant.

Multivariate analysis. We first estimated the differences in outcomes between genders and between ethnic groups without adjusting for clinical need. We then adjusted for clinical need using variables to characterize patient acuity and comorbidity (see Appendix 1). We defined clinical need as hypertension, acute myocardial infarction, hemodialysis, a history of stroke, diabetes, chronic lung disease, congestive heart failure, age (measured as number of years older than age 65 years), and body mass index. We computed odds ratios and the corresponding $95 \%$ confidence intervals through an estimation of the logistic regression models.

\section{Survival Analysis}

Unadjusted survival estimates were calculated using Kaplan-Meier curves and were compared between men and women and then between white and nonwhite patients using the log-rank test. Cox proportional hazards models were computed to adjust the interval to death for patients with differing survival follow-up times (Appendix 2). The subjects who were alive at the end of our follow-up period were censored. The patients who underwent subsequent AVR were also censored . All analyses were conducted using SAS, version 9.2 (SAS Institute, Cary, NC).

\section{RESULTS}

\section{Univariate Analysis}

Men versus women. The patient characteristics stratified by gender and race are listed in Table 1 . Men were more likely to be younger $(P<.0001)$, have a lower body mass in$\operatorname{dex}(P=.001)$, have diabetes $(P=.010)$, have experienced acute myocardial infarction $(P<.0001)$, require hemodialysis $(P=.037)$, have undergone percutaneous coronary intervention before surgery $(P<.001)$ and previous CABG $(P<.001)$, have a lower ejection fraction $(P<.0001)$, and have postoperative septicemia $(P=.009)$ than were the women. The women were more likely to have congestive heart failure $(P<.0001)$, hypertension $(P=.006)$, undergone previous valve surgery $(P=.001)$ and experienced postoperative stroke $(P=.031)$ than were the men.

White versus nonwhite. The nonwhite patients were younger $(P<.0001)$ and more likely to have diabetes $(P<.0001)$ and congestive heart failure $(P=.029)$, more likely to require hemodialysis $(P<.0001)$, and to have undergone previous valve surgery $(P=.001)$. They were less likely to have undergone previous CABG $(P=.008)$, to have a mechanical prosthesis $(P<.0001)$, to have a lower cardiopulmonary bypass time $(P=.029)$, to have a lower crossclamp time $(P=.031)$, and to receive a smaller prosthesis type $(P<.0001)$ than were the white patients.

The postoperative outcomes stratified by both gender and race are presented in Table 2. Nonwhite male patients were younger $(P<.0001)$ and were more likely to have diabetes $(P<.0001)$, require hemodialysis $(P=.001)$, and have undergone previous valve surgery $(P=.02)$. They were less likely to have undergone previous CABG $(P=.036)$, to undergo surgery on urgent or emergent basis $(P<.0001)$, to receive a smaller prosthesis type $(P<.0001)$, and to have postoperative acute myocardial infarction $(P=.004)$ than were white male patients (Table 2) . Nonwhite female patients were younger $(P<.0001)$ and were more likely to have diabetes $(P=.043)$, have undergone previous valve surgery $(P=.025)$, require hemodialysis $(P<.0001)$, have a lower crossclamp time $(P=.035)$, and receive a smaller prosthesis type $(P=.003)$ and more likely to receive a mechanical valve $(P<.0001)$ compared with white female patients (Table 2).

\section{Survival Analysis}

Unadjusted Kaplan-Meier survival curves are presented in Figures 1 and 2. A total of 27 patients underwent additional AVR surgery and were censored. Survival was no different between the male and female patients $(P=.796)$. Similarly, no difference in survival rates was 
TABLE 1. Preoperative, intraoperative, and postoperative characteristics by gender and race

\begin{tabular}{|c|c|c|c|c|c|c|}
\hline \multirow[b]{2}{*}{ Characteristic } & \multicolumn{6}{|c|}{ Hospital admissions } \\
\hline & $\operatorname{Men}(n=4043)$ & Women $(n=2766)$ & $P$ value & White $(n=6481)$ & Nonwhite $(n=328)$ & $P$ value \\
\hline Age (y) & $71.0 \pm 11.0$ & $73.9 \pm 10.3$ & $<.0001$ & $72.5 \pm 10.7$ & $66.8 \pm 12.4$ & $<.0001$ \\
\hline BMI $\left(\mathrm{kg} / \mathrm{m}^{2}\right)$ & $28.5 \pm 6.7$ & $29.0 \pm 7.2$ & .001 & $28.7 \pm 6.9$ & $28.6 \pm 5.9$ & .738 \\
\hline BSA & $2.0 \pm 0.2$ & $1.8 \pm 0.2$ & $<.0001$ & $1.9 \pm 0.2$ & $1.8 \pm 0.2$ & $<.0001$ \\
\hline $\mathrm{EF}(\%)$ & $53.3 \pm 13.9$ & $58.0 \pm 11.8$ & $<.0001$ & $55.2 \pm 13.3$ & $55.2 \pm 13.8$ & .970 \\
\hline Hypertension & $3058(75.6)$ & $2170(78.5)$ & .006 & $4976(76.8)$ & $252(76.8)$ & .987 \\
\hline AMI & $916(22.7)$ & $439(15.9)$ & $<.0001$ & $1286(19.8)$ & $69(21.0)$ & .597 \\
\hline Hemodialysis & $83(2.1)$ & $38(1.4)$ & .037 & $102(1.6)$ & $19(5.8)$ & $<.0001$ \\
\hline History of stroke & $279(6.9)$ & $194(7.0)$ & .856 & 445 (6.9) & $28(8.5)$ & .246 \\
\hline Diabetes & $1246(30.8)$ & 772 (27.9) & .010 & $1884(29.1)$ & 134 (40.9) & $<.0001$ \\
\hline Infectious endocarditis & $48(1.2)$ & $20(0.7)$ & .059 & $62(1.0)$ & $6(1.8)$ & .121 \\
\hline Previous valve surgery & $84(2.1)$ & $94(3.4)$ & .001 & $160(2.5)$ & $18(5.5)$ & .001 \\
\hline Previous CABG & $447(11.1)$ & $138(5.0)$ & $<.0001$ & $570(8.8)$ & $15(4.6)$ & .008 \\
\hline Previous PCI & $586(14.5)$ & $236(8.5)$ & $<.0001$ & $788(12.2)$ & $34(10.4)$ & .331 \\
\hline Chronic lung disease & & & .129 & & & .354 \\
\hline None & 3343 (82.7) & 2277 (82.4) & & $5339(82.4)$ & $281(85.7)$ & \\
\hline Mild & $385(9.5)$ & $301(10.9)$ & & $659(10.2)$ & $27(8.2)$ & \\
\hline Moderate & $205(5.1)$ & $126(4.6)$ & & $320(4.9)$ & $11(3.4)$ & \\
\hline Severe & $110(2.7)$ & $61(2.2)$ & & $162(2.5)$ & $9(2.7)$ & \\
\hline $\mathrm{CHF}$ & $1401(34.7)$ & $1119(40.5)$ & $<.0001$ & $2380(36.7)$ & $140(42.7)$ & .029 \\
\hline Case priority & & & .082 & & & $<.0001$ \\
\hline Elective & $2646(65.4)$ & $1773(64.1)$ & & $4243(65.5)$ & $176(53.7)$ & \\
\hline Urgent & $1356(33.5)$ & $976(35.3)$ & & DS* & DS* & \\
\hline Emergent & $41(1.0)$ & $17(0.6)$ & & DS* & DS* & \\
\hline \multicolumn{7}{|l|}{ Intraoperative } \\
\hline Prosthesis type & & & .092 & & & $<.0001$ \\
\hline Mechanical & $477(11.8)$ & $290(10.5)$ & & $708(10.9)$ & $59(18.0)$ & \\
\hline Bioprosthesis & $3566(88.2)$ & $2476(89.5)$ & & $5776(89.1)$ & $269(82.0)$ & \\
\hline Mean gradient across aortic valve & $45.9(18.0)$ & $50.1(19.0)$ & $<.0001$ & $47.7(18.5)$ & $46.8(18.5)$ & .419 \\
\hline CPB time (min) & $140.8(52.2)$ & $124.7(47.2)$ & $<.0001$ & $134.6(50.9)$ & $128.3(49.1)$ & .029 \\
\hline Crossclamp time (min) & $105.8(40.3)$ & $93.1(36.5)$ & $<.0001$ & $100.9(39.3)$ & $96.1(38.3)$ & .031 \\
\hline Aortic implant size & $23.3(1.9)$ & $20.8(1.5)$ & $<.0001$ & $22.3(2.2)$ & $21.5(2.0)$ & $<.0001$ \\
\hline Median & 23.0 & 21.0 & & 23.0 & 21.0 & \\
\hline Range & 17.0 & 11.0 & & 19.0 & 10.0 & \\
\hline \multicolumn{7}{|l|}{ Postoperative } \\
\hline AMI & $548(13.6)$ & $302(10.9)$ & .001 & $818(12.6)$ & $32(19.8)$ & .126 \\
\hline Stroke & $89(2.2)$ & $84(3.0)$ & .031 & $162(2.5)$ & $11(3.4)$ & .338 \\
\hline $\mathrm{ARF}$ & $191(4.7)$ & $105(3.8)$ & .065 & $278(4.3)$ & $18(5.5)$ & .299 \\
\hline Septicemia & $82(2.0)$ & $33(1.2)$ & .009 & DS* & DS* & .265 \\
\hline Hemodialysis & $64(1.6)$ & $49(1.8)$ & .552 & DS* & DS* & .844 \\
\hline Pericardial tamponade & $21(0.5)$ & $13(0.5)$ & .776 & DS* & DS* & .771 \\
\hline Reoperation for bleeding & $140(3.5)$ & $76(2.7)$ & .098 & $208(3.2)$ & $8(2.4)$ & .437 \\
\hline Any reoperation & $261(6.5)$ & $161(5.8)$ & .286 & $404(6.2)$ & $18(5.5)$ & .585 \\
\hline \multicolumn{7}{|l|}{ Mortality } \\
\hline $30 \mathrm{~d}$ & $107(2.6)$ & $85(3.1)$ & .296 & $180(2.8)$ & $12(3.7)$ & .342 \\
\hline $1 \mathrm{y} \dagger$ & $292(8.2)$ & $201(8.0)$ & .796 & $471(8.2)$ & $22(7.1)$ & .526 \\
\hline
\end{tabular}

Data presented as mean \pm standard deviation or numbers, with percentages in parentheses. $B M I$, Body mass index; $B S A$, body surface area; $E F$, ejection fraction; $A M I$, acute myocardial infarction; $C A B G$, coronary artery bypass grafting; $P C I$, percutaneous coronary intervention; $C H F$, congestive heart failure; $C P B$, cardiopulmonary bypass; $A R F$, acute renal failure; $D S$, data suppressed. *Cells suppressed according to Massachusetts Department of Public Health reporting guidelines. If a cell contained a frequency $<6$ (or enabled determination of a cell frequency $<6$ ), cells were suppressed. †Excluded non-Massachusetts residents $(473$ male and 252 female nonresidents and 705 white and 20 nonwhite nonresidents).

observed between whites and nonwhites $(P=.526)$. No difference was seen in survival between the AVR and AVR plus CABG patients in the different gender and ethnic groups (data not shown).

\section{Multivariate Analysis}

On multivariate logistic regression analysis, no differences were observed in mortality between the women and men (odds ratio $[\mathrm{OR}], 0.88$; 95\% confidence interval $[\mathrm{CI}], 0.26-3.02$; 
TABLE 2. Preoperative, intraoperative, and postoperative characteristics by gender and race

\begin{tabular}{|c|c|c|c|c|c|c|}
\hline Variable & White men & Nonwhite men & $P$ value & White women & Nonwhite women & $P$ value \\
\hline Admissions & 3866 & 177 & & 2615 & 151 & \\
\hline \multicolumn{7}{|l|}{ Preoperative } \\
\hline Age (y) & $71.3 \pm 10.9$ & $65.8 \pm 12.2$ & $<.0001$ & $74.3 \pm 10.0$ & $68.2 \pm 12.5$ & $<.0001$ \\
\hline BMI $\left(\mathrm{kg} / \mathrm{m}^{2}\right)$ & $28.5 \pm 6.7$ & $28.4 \pm 5.6$ & .805 & $29.1 \pm 7.3$ & $28.8 \pm 6.2$ & .735 \\
\hline BSA & $2.0 \pm 0.2$ & $1.9 \pm 0.2$ & $<.0001$ & $1.8 \pm 0.2$ & $1.7 \pm 0.2$ & .061 \\
\hline $\mathrm{EF}(\%)$ & $53.3 \pm 13.8$ & $53.3 \pm 14.9$ & .843 & $58.0 \pm 11.9$ & $57.9 \pm 11.7$ & .905 \\
\hline Hypertension & 2925 (75.7) & $133(75.1)$ & .875 & $2051(78.5)$ & 119 (78.8) & .920 \\
\hline AMI & $877(22.7)$ & $39(22.0)$ & .840 & $409(15.6)$ & $30(19.9)$ & .167 \\
\hline Hemodialysis & $73(1.9)$ & $10(5.6)$ & .001 & $29(1.1)$ & $9(6.0)$ & $<.0001$ \\
\hline History of stroke & $263(6.8)$ & $16(9.0)$ & .251 & $182(7.0)$ & $12(7.9)$ & .645 \\
\hline Diabetes & $1165(30.1)$ & $81(45.8)$ & $<.0001$ & $719(27.5)$ & $53(35.1)$ & .043 \\
\hline Infectious endocarditis & DS* & DS* & .040 & DS* & $\mathrm{DS}^{*}$ & .927 \\
\hline Previous valve surgery & $76(2.0)$ & $8(4.5)$ & .020 & $84(3.2)$ & $10(6.6)$ & .025 \\
\hline Previous CABG & $436(11.3)$ & $11(6.2)$ & .036 & DS* & $\mathrm{DS}^{*}$ & .174 \\
\hline Previous PCI & $564(14.6)$ & $22(12.4)$ & .425 & $224(8.6)$ & $12(7.9)$ & .791 \\
\hline Chronic lung disease & & & .473 & & & .639 \\
\hline None & 3192 (82.6) & $151(85.3)$ & & $2147(82.1)$ & $130(86.1)$ & \\
\hline Mild & $370(9.6)$ & $15(8.5)$ & & $289(11.1)$ & $12(7.9)$ & \\
\hline Moderate & DS* & DS* & & DS* & DS* & \\
\hline Severe & DS* & DS* & & DS* & DS* & \\
\hline $\mathrm{CHF}$ & $1330(34.4)$ & $71(40.1)$ & .119 & $1050(40.2)$ & $69(45.7)$ & .177 \\
\hline Case priority & & & $<.0001$ & & & .116 \\
\hline Elective & $2557(66.1)$ & $89(50.3)$ & & $1686(64.5)$ & $87(57.6)$ & \\
\hline Urgent & DS* & DS* & & $912(34.9)$ & $64(42.4)$ & \\
\hline Emergent & DS* & DS* & & $17(0.7)$ & $0(0.0)$ & \\
\hline \multicolumn{7}{|l|}{ Intraoperative } \\
\hline Mean gradient across aortic valve & $45.9(17.9)$ & $45.8(19.5)$ & .902 & $50.2(19.1)$ & $48.0(17.4)$ & .169 \\
\hline Perfusion time (min) & $141.0(52.4)$ & $135.4(49.0)$ & .162 & $125.0(47.2)$ & $119.9(48.2)$ & .195 \\
\hline Crossclamp time (min) & $105.9(40.3)$ & $103.8(40.5)$ & .509 & 93.5 (36.6) & $87.0(33.3)$ & .035 \\
\hline Aortic implant size & $23.4(1.9)$ & $22.5(1.8)$ & $<.0001$ & $20.8(1.5)$ & $20.4(1.5)$ & .003 \\
\hline Median & 23.0 & 23.0 & & 21.0 & 21.0 & \\
\hline Range & 17.0 & 10.0 & & 11.0 & 8.0 & \\
\hline Prosthesis type & & & .053 & & & .0001 \\
\hline Mechanical & 448 (11.6) & $29(16.4)$ & & $260(9.9)$ & $30(19.9)$ & \\
\hline Bioprosthesis & $3418(88.4)$ & $148(83.6)$ & & $2355(90.1)$ & $121(80.1)$ & \\
\hline \multicolumn{7}{|l|}{ Postoperative } \\
\hline AMI & 537 (13.9) & $11(6.2)$ & .004 & $281(10.7)$ & $21(13.9)$ & .226 \\
\hline Stroke, permanent & $83(2.1)$ & $6(3.4)$ & .270 & DS* & DS* & .840 \\
\hline Renal failure & $183(4.7)$ & $8(4.5)$ & .896 & $95(3.6)$ & $10(6.6)$ & .062 \\
\hline Reoperation for bleeding & DS* & DS* & .083 & $70(2.7)$ & $6(4.0)$ & .343 \\
\hline Any reoperation & $254(6.6)$ & $7(4.0)$ & .166 & $150(5.7)$ & $11(7.3)$ & .429 \\
\hline \multicolumn{7}{|l|}{ Mortality } \\
\hline $30 \mathrm{~d}$ & $100(2.6)$ & $7(4.0)$ & .261 & DS* & DS* & .862 \\
\hline $1 \mathrm{y} \dagger$ & $280(8.2)$ & $12(7.3)$ & .664 & $191(8.1)$ & $10(7.0)$ & .649 \\
\hline
\end{tabular}

Data presented as mean \pm standard deviation or numbers, with percentages in parentheses. $B M I$, Body mass index; $B S A$, body surface area; $E F$, ejection fraction; $A M I$, acute myocardial infarction; $C A B G$, coronary artery bypass grafting; $P C I$, percutaneous coronary intervention; $C H F$, congestive heart failure; $C P B$, cardiopulmonary bypass; $A R F$, acute renal failure; $D S$, data suppressed. *Cells suppressed according to Massachusetts Department of Public Health reporting guidelines. If a cell contained a frequency $<6$ (or enabled determination of a cell frequency $<6$ ), cells were suppressed. †Excluded non-Massachusetts residents $(473$ male and 252 female nonresidents and 705 white and 20 nonwhite nonresidents).

$P=.84)$. We did not observe differences in mortality between nonwhites and whites (OR, 1.57; 95\% CI, 0.45-5.44; $P=.48)$. Also, no significant difference was seen in mortality between the nonwhite men and white men (OR, 1.56; 95\% CI, $0.70-3.47 ; P=.28$ ) or between the nonwhite women and white women (OR, 1.01; 95\% CI, 0.39-2.58; $P=.99$ ).

\section{DISCUSSION}

A large body of evidence has documented disparities in surgical outcomes. Most of the disparities research has focused on the effects of gender or race on the outcomes of cardiac surgery. For example, the risk of mortality with CABG remained 29\% greater among nonwhites than 


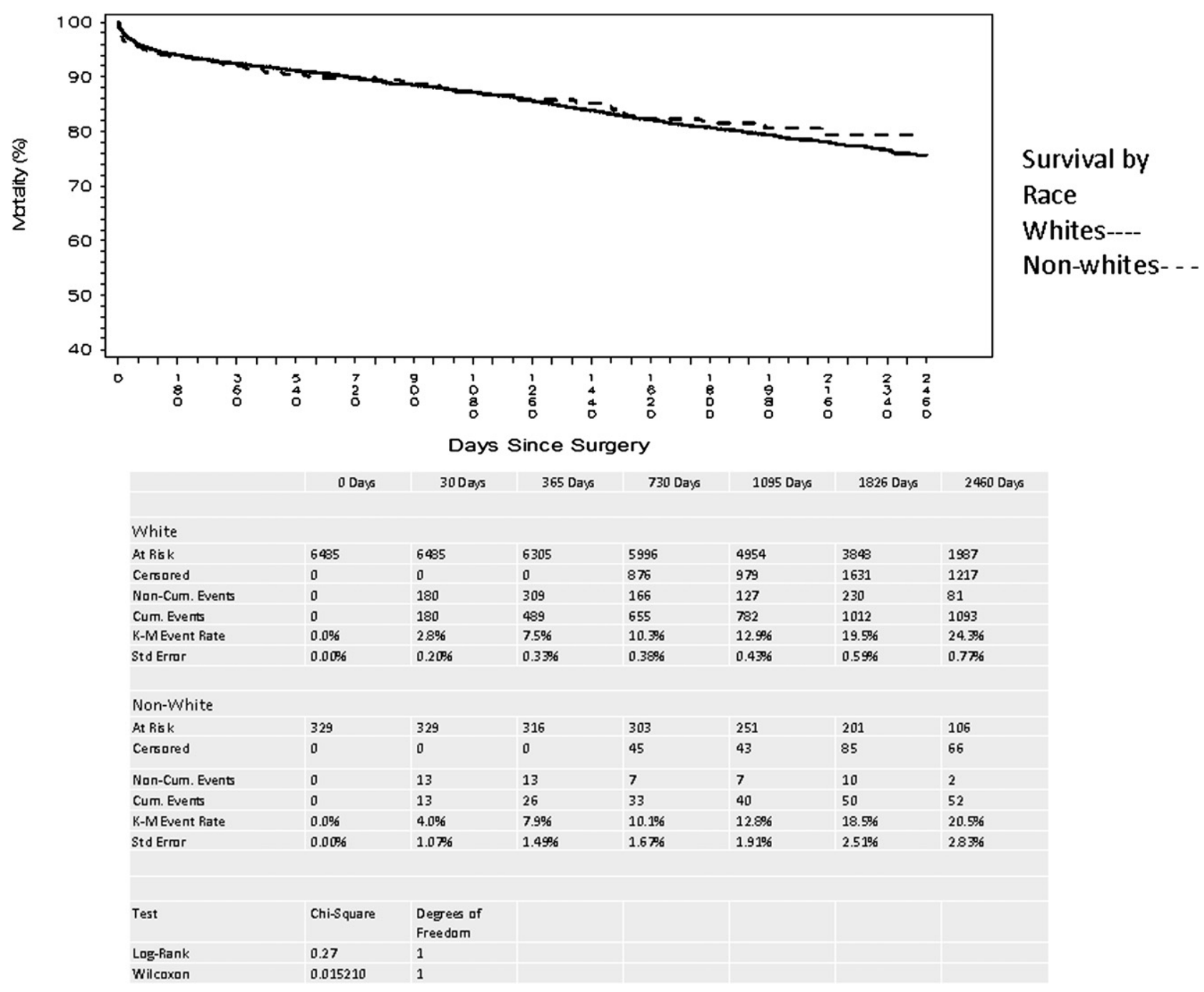

FIGURE 1. Kaplan-Meier survival curves by race, with no difference in survival found between whites and nonwhites.

whites after adjusting for 27 other risk factors. ${ }^{12}$ Female gender has also been associated with increased mortality after CABG, primarily because of the unfavorable preoperative risk profile in women. Women are reported to be older, have smaller target vessels, and have a greater prevalence of comorbidities. ${ }^{11-13}$ A scarcity of studies has evaluated the interaction between gender and race on the outcomes of AVR.

\section{Principal Findings}

In our study, no significant difference was found in the risk-adjusted 1-year mortality between genders or between racial groups after AVR in Massachusetts. White men were more likely to experience postoperative acute myocardial infarction than were nonwhite men. Women were more likely to experience postoperative stroke than were men, and men had a greater risk of experiencing postoperative septicemia than did women. That postoperative stroke was more common in women might have been related to the greater rate of hypertension and the more advanced age of the women compared with the men undergoing AVR.

Significant differences were found in the patient characteristics as a function of gender or race. The nonwhite patients were younger and presented more frequently with congestive heart failure than did the white patients. The nonwhite men underwent a significantly greater proportion of urgent or emergent surgery compared with the white men. This finding indicates disparate access or use of appropriate preventive care and diagnostic evaluation for nonwhite patients, as previously documented. ${ }^{5}$ Previous investigators have demonstrated disparate access to cardiac catheterization, transcatheter interventions, and CABG for nonwhite patients. ${ }^{14,15}$

In both racial groups, men were more likely than women to undergo AVR. Certain comorbidities, such as renal failure requiring hemodialysis, congestive heart failure, and 


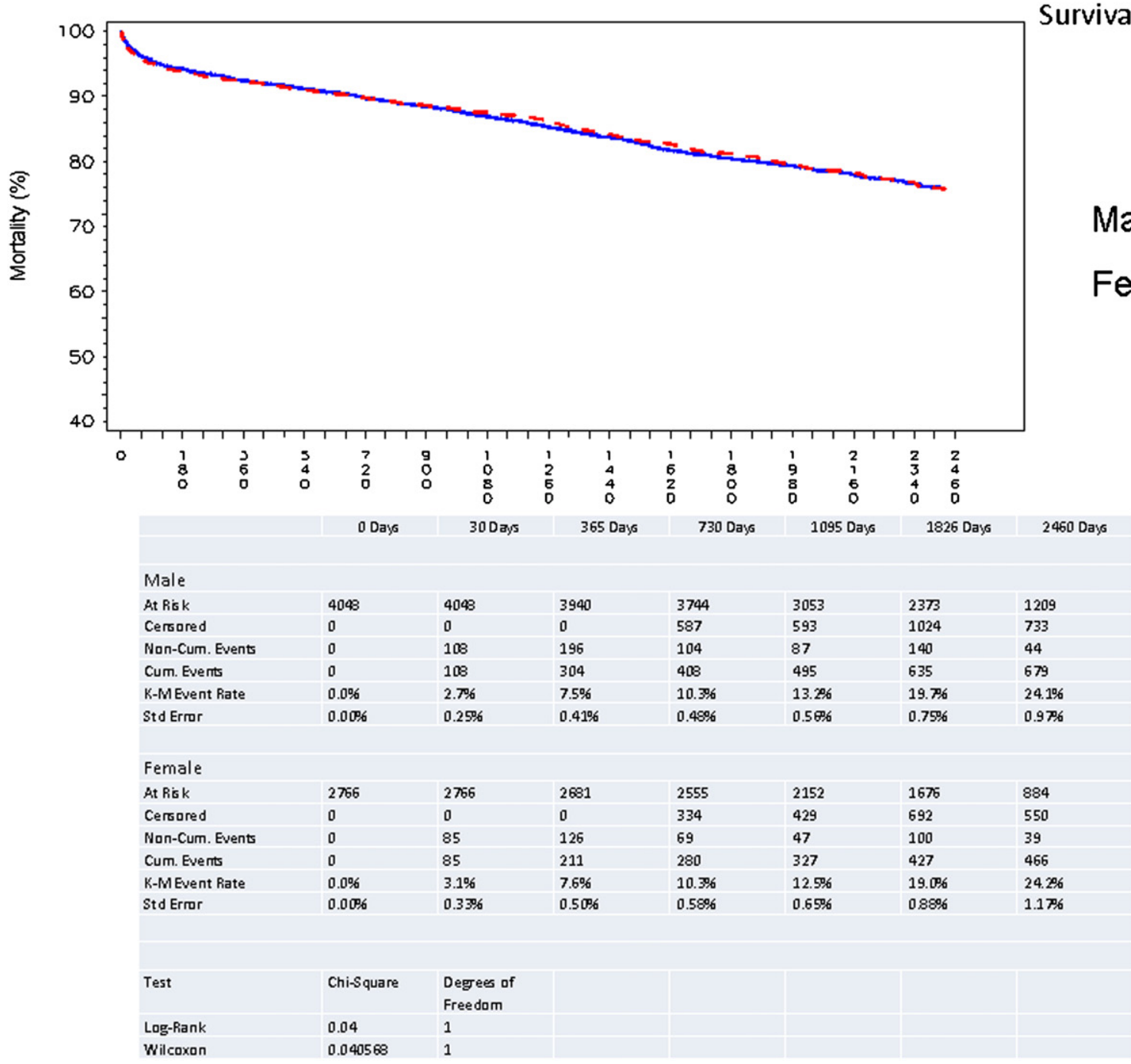

FIGURE 2. Kaplan-Meier survival curves by gender, with no difference in survival found between men and women.

diabetes, were more frequent in the nonwhite population because of the greater prevalence of these comorbidities in the nonwhite population. ${ }^{5}$ That the nonwhite male and female patients received a greater percentage of mechanical valves than the white patients was likely related to the younger age at presentation for the nonwhite patients compared with the white patients. That more mechanical valves were implanted in the nonwhite than in the white patients and that, on average, mechanical valves have a greater effective orifice area for the same size of prosthesis compared with the bioprosthetic valves partially explains the finding that smaller prostheses were implanted in the nonwhite patients than in the white patients. Furthermore, nonwhite patients had a smaller body surface area than did the white patients (nonwhite body surface area, $1.8 \pm 0.2$ versus $1.9 \pm 0.2$ for whites; $P<.0001$ ), necessitating implantation of a smaller size prosthesis. The smaller body surface area of the nonwhite patients might also explain the more expedient surgery for nonwhite patients compared with the white patients, as indicated by the lower cardiopulmonary bypass and crossclamp time for the nonwhite patients than for the white patients.

Clinical implications. In our study, gender and race did not appear to be associated with an increased risk of mortality after AVR. The risk of stroke was greater for women after AVR than for men. Racial discrepancies to access to preventive medicine and referral for expert cardiovascular care might explain the more urgent or emergent nature of AVR in the nonwhite population.

Study limitations. The limitations of the present study include all those inherent to any retrospective, single-state analysis. The present study was a nonrandomized study in which unmeasured patient- or procedure-related variables could have influenced the study results. For our racial comparison, we might have been underpowered to detect differences owing to the relatively small number of nonwhite 
patients. All the data for our study were drawn from the State of Massachusetts database, which is not necessarily representative of all cardiac surgery practices in the United States. The sample size was also a limitation in that the number of nonwhite patients undergoing AVR in Massachusetts was small. Another limitation of our study was that the Society for Thoracic Surgeons' risk score was not available during the study period. Furthermore, future studies are required to evaluate the role of transcutaneous aortic valve replacement in the subset of patients who need AVR and have probably too high a surgical risk to undergo conventional AVR. Among the strengths of the present study were the large cohort of patients and the prospective entry of all data elements into a cardiac surgical database with strict definitions.

\section{References}

1. Doenst T, Ivanov J, Borger MA, David TE, Brister SJ. Sex-specific long-term outcomes after combined valve and coronary artery surgery. Ann Thorac Surg. 2006;81:1632-6.

2. Vaccarino V, Koch CG. Long-term benefits of coronary bypass surgery: are the gains for women less than for men? J Thorac Cardiovas Surg. 2003;126: 1707-11.

3. Wenger NK. Is what's good for the gander good for the goose? J Thorac Cardiovasc Surg. 2003;126:929-31.

APPENDIX 1. Odds ratios and $95 \%$ confidence intervals) of mortality after isolated AVR or isolated AVR plus CABG

\begin{tabular}{|c|c|c|}
\hline $\begin{array}{l}\text { All isolated AVR or isolated } \\
\text { AVR + CABG admissions }\end{array}$ & OR $(95 \%$ CI $)$ & $\begin{array}{c}P \\
\text { value }\end{array}$ \\
\hline \multicolumn{3}{|l|}{ 30-Day mortality } \\
\hline \multicolumn{3}{|l|}{ Gender disparity: women relative to men } \\
\hline Without adjustment for clinical need & $0.98(0.29-3.28)$ & .98 \\
\hline With adjustment for clinical need & $0.88(0.26-3.02)$ & .84 \\
\hline \multicolumn{3}{|l|}{ Race disparity: nonwhites relative to whites } \\
\hline Without adjustment for clinical need & $1.69(0.51-5.65)$ & .39 \\
\hline With adjustment for clinical need & $1.57(0.45-5.44)$ & .48 \\
\hline \multicolumn{3}{|l|}{ Nonwhite men relative to white men } \\
\hline Without adjustment for clinical need & $1.56(0.71-3.41)$ & .26 \\
\hline With adjustment for clinical need & $1.56(0.70-3.47)$ & .28 \\
\hline \multicolumn{3}{|l|}{ Nonwhite women relative to white women } \\
\hline Without adjustment for clinical need & $1.08(0.43-2.72)$ & .86 \\
\hline With adjustment for clinical need & $1.01(0.39-2.58)$ & .99 \\
\hline \multicolumn{3}{|l|}{ 1-Year mortality } \\
\hline \multicolumn{3}{|l|}{ Gender disparity: women relative to men } \\
\hline Without adjustment for clinical need & $0.94(0.38-2.29)$ & .89 \\
\hline With adjustment for clinical need & $0.83(0.33-2.11)$ & .69 \\
\hline \multicolumn{3}{|l|}{ Race disparity: nonwhites relative to whites } \\
\hline Without adjustment for clinical need & $0.75(0.31-2.29)$ & .53 \\
\hline With adjustment for clinical need & $0.76(0.30-1.95)$ & .57 \\
\hline \multicolumn{3}{|l|}{ Nonwhite men relative to white men } \\
\hline Without adjustment for clinical need & $0.88(0.48-1.60)$ & .66 \\
\hline With adjustment for clinical need & $0.87(0.47-1.64)$ & .68 \\
\hline \multicolumn{3}{|l|}{ Nonwhite women relative to white women } \\
\hline Without adjustment for clinical need & $0.86(0.44-1.66)$ & .65 \\
\hline With adjustment for clinical need & $0.87(0.44-1.73)$ & 69 \\
\hline
\end{tabular}

Raw 30-day mortality rate, $2.8 \%$; observed 1-year mortality rate, $8.1 \%$. OR, Odds ratio; $A V R$, aortic valve replacement; $C A B G$, coronary artery bypass grafting.
4. Hartz RS, Swain JA, Mickleborough L. Sixty-year perspective on coronary artery bypass grafting in women. $J$ Thorac Cardiovas Surg. 2003;126:620-2.

5. Taylor NE, O'Brien S, Edwards FH, Peterson ED, Bridges CR. Relationship between race and mortality and morbidity after valve replacement surgery. Circulation. 2005;111:1305-12.

6. Bridges CR, Edwards FH, Peterson ED, Coombs LP. The effect of race on coronary bypass operative mortality. J Am Coll Cardiol. 2000;36:1870-6.

7. Koch CG, Khandwala F, Nussmeier N, Blackstone EH. Gender profiling in coronary artery bypass grafting. J Thorac Cardiovasc Surg. 2003;126:2044-51.

8. Ibrahim MF, Paparella D, Ivanov J, Buchanan MR, Brister SJ. Gender-related differences in morbidity and mortality during combined valve and coronary surgery. J Thorac Cardiovasc Surg. 2003;126:959-64.

9. Bridges CR, Edwards FH, Peterson ED, Coombs LP, Ferguson TB. Cardiac surgery in nonagenarians and centenarians. J Am Coll Surg. 2003;197:347-57.

10. Rumsfeld JS, Plomondon ME, Peterson ED, Shlipak MG, Maynard C, Grunwald GK, et al. The impact of ethnicity on outcomes following coronary artery bypass graft surgery in the Veteran's Health Administration. J Am Coll Cardiol. 2002;40:1786-93.

11. Edwards FH, Carey JS, Grover FL, Bero JW, Hartz RS. Impact of gender on coronary bypass operative mortality. Ann Thorac Surg. 1998;66:125-31.

12. Vaccarino V, Abramson JL, Veledar E, Weintraub WS. Sex differences in hospital mortality after coronary artery bypass surgery: evidence for a higher mortality in younger women. Circulation. 2002;105:1176-81.

13. Vaccarino V, Lin ZQ, Kasl SV, Mattera JA, Roumanis SA, Abramson JL, Krumholz HM. Gender differences in recovery after coronary artery bypass surgery. J Am Coll Cardiol. 2003;41:307-14.

14. Gillum RF, Gillum BS, Francis CK. Coronary revascularization and cardiac catheterization in the United States: trends in racial differences. Am Coll Cardiol. 1997;29:1557-62.

15. Bridges CR. Cardiac surgery in African Americans. Ann Thorac Surg. 2003;76: S1356-62.

APPENDIX 2. Cox proportional hazard analysis of maximum likelihood estimates

\begin{tabular}{lccr}
\hline \multicolumn{1}{c}{ Variable } & HR & $\mathbf{9 5 \%}$ CI & P value \\
\hline Gender_race & & & \\
$\quad$ Nonwhite women & 0.791 & $0.535-1.171$ & .2412 \\
$\quad$ Nonwhite men & 0.849 & $0.585-1.234$ & .3920 \\
$\quad$ White women & 0.900 & $0.802-1.010$ & .0726 \\
Hypertension & 0.984 & $0.858-1.127$ & .8126 \\
Myocardial infarction & 1.414 & $1.251-1.599$ & $<.0001$ \\
Dialysis & 4.487 & $3.514-5.730$ & $<.0001$ \\
Stroke & 1.496 & $1.256-1.781$ & $<.0001$ \\
Diabetes & 1.450 & $1.290-1.631$ & $<.0001$ \\
Moderate/severe COPD & 1.822 & $1.549-2.144$ & $<.0001$ \\
Congestive heart failure & 1.671 & $1.492-1.872$ & $<.0001$ \\
Age $>65$ y & 1.047 & $1.039-1.054$ & $<.0001$ \\
Body mass index & 0.985 & $0.974-0.995$ & .0045 \\
\hline
\end{tabular}

HR, Hazard ratio; $C I$, confidence interval; $C O P D$, chronic obstructive pulmonary disease. 